\title{
The Moderating Role of Gender on Pathos and Logos in Online Shopping Behavior
}

\author{
Vishal Verma, Babasaheb Bhimrao Ambedkar University, India \\ (iD) https://orcid.org/0000-0001-8570-6691 \\ Swati Anand, Babasaheb Bhimrao Ambedkar University, India \\ (iD) https://orcid.org/0000-0001-5752-1892 \\ Kushendra Mishra, Babasaheb Bhimrao Ambedkar University, India \\ iD https://orcid.org/0000-0002-1404-2581
}

\begin{abstract}
Many research studies and observations have made it evident that there exists a difference between the shopping behavior of the male and female. The objective of this research paper is to explore the moderation effect of gender on the influence of pathos and logos in online shopping. Pathos can be explained as the emotional quotient in the purchasing behavior whereas logos can be understood as the logic behind purchasing a particular product. Structural equation modeling is used for the final analysis and interpretation of the formulated hypothesis. The three approaches used are chi-square difference, pairwise parameter comparisons, and nested model comparisons to know the moderating role of gender on the relationship between pathos and logos in online shopping. The findings of this research conclude that females are more governed by emotions, which is a complex buying behavior. The practical implication of this research paper is beneficial not only for the customers who frequently purchase the goods online but also for the e-commerce companies who are in the online trading business.
\end{abstract}

\section{KEYWORDS}

Chi-Square Difference, Emotion, Logic, Multiple Groups, Nested Model, Online Goods Purchasing, Pairwise Parameter, Structural Equation Modelling

\section{INTRODUCTION}

Rhetoric is a way of speaking or writing that is intended to impress or influence people. Rhetoric is defined as "an ability, in each particular case, to see the available means of persuasion". Aristotle viewed rhetorical appeals to ethos (credibility), pathos (emotion), and logos (reason) as means of persuasion. To effectively persuade the audience, three important persuasive appeals are identified ethos, pathos, and logos corresponding to the persona of the speaker, the emotion of the audience, and the reason for the message. (Isai et al., 2020) The classical rhetoric to digital rhetoric emerged a new concept of persuasion in the environment of social media where consumer-to-consumer conversation and persuasion helped in the selection of products and services. (Gabriel et al., 2016) Ethos is concerned with the trustworthiness or authority, tone/style. Pathos is concerned with emotional impact, personal connection, and logos are concerned with the reason, facts, statistics,

DOI: 10.4018/IJAMTR.288508

This article published as an Open Access article distributed under the terms of the Creative Commons Attribution License (http://creativecommons.org/licenses/by/4.0/) which permits unrestricted use, distribution, and production in any medium, provided the author of the original work and original publication source are properly credited. 
case studies, scientific evidence. In this continuation, karios is another mode of persuasion that is all about the right time and right place. It is defined as, an argument at the wrong time or to the wrong consumers will be wasted; to be effective, you must also consider when you are speaking and to whom. At a specific time like festivals or Valentine's day, Christmas, the consumers can be more attracted to the particular products and services. In the business world, every organization tries to impress or influence their customer using print and online media. Out of three, logos (Logic) is the most important element where the companies use the alphanumeric in the name of the product like iPhone XS and XR, MI Realme 9A, Samsung Galaxy M02 which looks the scientific or logical products. The Ethos represents the credibility issues; Pathos explains the emotional issues. In this study, the researcher focussed only on the two aspects, pathos and logos to consumer behavior in online shopping. In online shopping, consumers have more choices as compared to traditional shopping. There is a commendable increase in the e-commerce industry in the last couple of years. Online shopping is beneficial for both consumers as well as merchants. With the fast-growing technology, online shopping is emerging in India at a very faster rate. Smartphone users have a significant role in the growth of e-commerce businesses in India. In several studies, the concept of pathos (appeal to emotion) and logos (appeal to logic) is used in the investigation of online purchasing behavior by smartphone users. Undoubtedly, emotions and logic play a vital role in any important decisions of personal and professional life. This study has focussed on the role of gender on pathos and logos while purchasing goods or services via various e-commerce sites and applications like Flipkart, Amazon, Snapdeal, etc. There exists a behavioral difference in the shopping pattern of both genders which has become the subject matter of this research. It is presumed that emotions play a vital role for females whereas logic plays a vital role for males. There have been several observations that females feel like shopping when stressed. Generally in this process of online shopping, the money is paid by the females if financially independent and from the wallet of the males, in cases otherwise. That male could be her father, spouse, or anyone else. This critical behavior of males and females is evaluated in this study. This research will critically examine the role of gender on the emotional and logical behavior of a customer in online shopping.

\section{LITERATURE REVIEW}

The authors have explored the various national and international journals for new information, new facts, and new knowledge on the rhetoric elements and their connection with consumer behavior. The previous authors have shared their views on this issue. The following concluding findings are as follows: The rhetoric is concerned with ethos, pathos, and logos. Ethos is the set of moral beliefs, ethics, attitudes, habits, etc., that are characteristic of a person or group. The word pathos means "suffering," "experience," or "emotion." The word logos is the reason or the rationality or the logical principle expressed in words and thoughts. (Wilkowski \& Park, 2015) The use of rhetorical tools is an important factor for effective negotiations. The rhetorical tools are ethos, pathos, and logos. These tools are used in effective business and marketing negotiations (Peleckis \& Peleckiene, 2015). The brand values are important, concerning the social and emotional traits of the consumers. For any organization, the brand image and brand value is the most valuable aspect of the business. The brand value is closely linked with the rhetorical characteristics of a person (Xiao et al., 2019). Persuasiveness is important for consumer's decision-making for a good selection. The decision-making for the selection of goods and services is always linked with persuasiveness (Das et al., 2014). Trust is very important for the consumer buying process. Consumer loyalty and trust is the key to the success of any business organization. The rhetorical analysis is effective in social and economic analysis. Ethos, pathos, and logos are used in the business world (Higgins\&Walker,2012). One of the best ways to reduce the perceptions of risk that women associate with a given site may be to take actions that both reduce the risks of buying from that site and give women an incentive for sharing their positive experiences with their friends. (Garbarino \& Strahilevitz, 2004) Advertisement is considered 
transformational. The advertisement and marketing are associated with the sales and merchandise of goods and services. It can transform the concept into reality (Kiholm \& Gårdemyr, 2017). The information helps in branding on social media. Business news is largely used in the branding of goods and services. Business information is the most valuable to customers and the market (Lee et al., 2018). Pathos (emotional appeal) was used by university students(Ting, 2018). Ethos is linked with trust, pathos is linked with emotion, and logos are linked with logic (McCormack, 2014). The product page is moderated by product type rather than the product price. The product merchandise is a tool to display the products effectively and efficiently in physical as well as online format (Chu et al., 2014). Credibility is important in buying. The trust, loyalty, and truthfulness is the key element of success for any business organization. The buying and selling process largely depends on these key factors (Kantharaju et al., 2018). The website content and variety are important in online purchasing. The website display is linked with the principle of the merchandising process of the effective and efficient presentation of goods and services (Jiradilok et al., 2014). Persuasion is used in the buying process. The reminding techniques of advertisement through print and online media are very effective in the buying and selling of goods and services (Bolatito, 2012). Consumers and cultural transformations are liked. Culture and business are also associated. The e-commerce companies try to encash the cultural and festive benefits for the profit-making of their business units (Scaraboto \& Pereira, 2013). Males contain a more positive attitude and more willingness to purchase than females online. That is because females are not secure and familiar with online purchasing. Males tend to have utilitarian motivation because they focus more on time-saving and convenience which is a rational approach to purchase online. (Lim \& Rashad, 2014) Convenience, cost-saving, and lack of sociality are the main reasons impacting male shoppers for internet shopping, and the primary factors affecting female shoppers for web-based shopping are fashion, adventure and sociality. (Sarkar, 2015) Pathos (Emotional behavior of a person) has an impact on online goods purchasing) without a mediator. Pathos (Emotional behavior of a person) has an impact on online goods purchasing) with the presence of mediator Logos (Logical behavior of a person). The findings conclude that the Pathos exerts its partial influence on the online goods purchasing through the mediating variable (Logos) (Verma et al., 2020). On exploring the previous researches on the rhetoric elements and its connection with online consumer behavior, there is urgent need to do the further study, hence in this research, the impact of pathos and logos on online goods purchasing and moderating role of gender on the relationship between pathos and logos in online goods purchasing are being studied. The existing literature has identified the importance of pathos and logos on online shopping behavior.

\section{RESEARCH GAP}

The research gap is identified as there is limited work that has been carried out on the relationship between the rhetoric elements and online consumers' behavior. In this study, whether gender plays an important role in online shopping behavior or not, is checked by using the techniques of moderation analysis. The moderation analysis can be performed by the use of statistical software. In the moderation analysis, the male and female respondent's behavior can be separately checked. This can be performed by dividing the total respondents into two parts as one part is male respondents and the other part is female respondents. Both the groups are separately observed in the moderation techniques. This study is a novel concept because, in online shopping behavior, no previous author checked the three approaches as Chi-square Difference Test, Pairwise Parameter Comparisons (Constrained Model), and Nested Model Comparisons in the study of moderating role of gender on pathos and logos in online shopping behavior.

\section{OBJECTIVES}

The following objectives are as follows: 
1. To study the impact of pathos and logos on online goods purchasing.

2. To know the moderating role of gender on the relationship between pathos and logos in online goods purchasing.

\section{HYPOTHESES}

The following null hypotheses are as follows:

H0: The influence of pathos, logos toward online purchasing behavior is not moderated by gender.

$\mathbf{H O}_{\mathbf{b}}$ : There is no significant difference between female and male group estimates of pathos, logos on online purchasing behavior.

$\mathrm{HO}_{\mathbf{c}}$ : The constrained model of male and female respondents is the same as that of the unconstrained model.

Based on the research objectives, the three null hypotheses are designed which tested the moderating role of gender on pathos and logos towards online purchasing using three approaches. The constrained model is defined as an assumption that the group estimate of female and male respondents are equal i.e. the group estimates of females $=$ the group estimate of male respondents. A model is termed as a constrained model when the estimates of both male and female groups are the same.

\section{METHODOLOGY}

The primary data was collected through online consumers having a smartphone. The selected respondents were frequent buyers of online goods. Data was collected through structured questionnaires that were self-administered with web-based applications. The sample size of this study was kept at 400. This data was collected from the fastest-growing metro city Lucknow which is the state capital of Uttar Pradesh, India. The data collection period was from $1^{\text {st }}$ December 2020 to 31 sts December 2020. Individual young users of the smartphone were considered as a sampling unit of the analysis. The non-probability snowball sampling technique was used for the required sample size. The preliminary testing or pilot study has been conducted with a sample of 40 respondents. Since only 380 responses were filled, hence it can be said that we received a $95.0 \%$ response rate from the respondents. In the final analysis, 142 were males and 238 were females were included. 50.53\% of respondents were from the age group of 20-30 years; hence most of the respondents were youth and frequent users of online shopping. The nominal scale has been used for demographics variables. Likert 5 point has been used for three constructs as Pathos, Logos, and Online Goods Purchase (OGP) ranging from 1 to 5 ( strongly disagree $=1$, strongly agree $=5$ ). For the confirmatory factor analysis, the measurement model has been designed. The SEM model has been used for the final analysis and interpretation of the formulated hypothesis. The SEM model is a combination of factor analysis and regression analysis. The SEM technique is very useful in the direct path analysis, mediating analysis, and moderator (group) analysis. In this research, only direct path analysis and moderator (group) analysis have been used. The three approaches used are Chi-square Difference Test, Pairwise Parameter Comparisons (Constrained Model), and Nested Model Comparisons to know the moderating role of gender on the relationship of pathos and logos in online goods purchasing. The demographic results have been designed using SPSS 23.0 version whereas the advanced analysis has been done through the AMOS 23.0 version.

\section{RELIABILITY AND VALIDITY}

The reliability, validity, and exploratory factor analysis (Principal Component Analysis) were used to test the questionnaire. The Cronbach's Alpha, Corrected Item Total Correlation (CITC), Kaiser- 
Table 1. Construct and variable type

\begin{tabular}{|l|l|l|}
\hline \multicolumn{1}{|c|}{ Latent Variable (Construct) } & \multicolumn{1}{c|}{ Variable Type } & \multicolumn{1}{c|}{ Scale } \\
\hline Pathos & Independent variable & Likert five points \\
\hline Logos & Independent variable & Likert five points \\
\hline Online Goods Purchasing & Dependent variable & Likert five points \\
\hline
\end{tabular}

Meyer-Olkin (KMO) values have been used for the finalization of each item under different constructs. For the finalization of items under different constructs, the min 0.70 Cronbach's alpha value has been set, the CITC (Corrected Item Total Correlation) value above 0.300 has been fixed and the KMO value above 0.6 is considered for better sampling adequacy test. The higher the value of KMO, the better it is. The convergent validity through Average Variance Extracted (AVE) is established on each construct. The Average Variance Extracted (AVE) is a measure of the amount of variance captured by a construct from each scale. The AVE has a recommended value of 0.50 or higher to provide evidence for convergent validity. Lastly, the discriminant validity was also established as AVE values came out to be greater than Squared Multiple Correlation (SMC) values. Squared multiple correlations (R) is also called the coefficient of determination which is defined as the proportion of the total variation explained by the model. Finally, the confirmatory factor analysis is also done for the finalization of each construct under the scale development and tool standardization process. All the required model fit indices (GFI, AGFI, TLI, CFI, NFI, and RMSEA) are used for good model fit. The minimum CMIN/DF is achieved for each construct under the measurement model and the structural model.

Cronbach's Alpha is 0.734 for the pathos, 0.796 for logos, and 0.803 for the online goods purchasing construct, hence all the constructs have passed the limit of 0.70 (min limit of Cronbach's alpha). KMO value is 0.708 for the pathos construct, 0.729 for the logos construct, and 0.761 for the online goods purchasing construct, hence the selected construct passed the sampling adequacy test. All the items of different constructs explained $49.409 \%, 56.450 \%, 58.036 \%$ variance under pathos, logos, and online goods constructs respectively.

The AVE and CR values are $0.494,0.828$ for pathos, $0.564,0.886$ for logos and $0.580,0.872$ for online goods purchasing. The min and max SMC values $0.220,0.375$ for pathos, $0.382,0.523$ for logos, $0.280,0.581$ for online goods purchasing constructs respectively. Lastly, the discriminant validity was also established as AVE values came out to be greater than Squared Multiple Correlation (SMC) values. The composite reliability values (CR) are also above 0.70 , therefore it can be said that all the results of reliability, validity and, exploratory factor analysis are acceptable (See Table 2).

In table 2, KMO, AVE, CR, and SMC are Kaiser-Meyer-Olkin, Average Variance Extracted, Composite Reliability, and Squared Multiple Correlation respectively. $\mathrm{N}$ is the number of items under pathos, logos, and OGP (online goods purchasing) constructs.

Table 2. Reliability, validity and, exploratory factor analysis results

\begin{tabular}{|l|l|l|l|l|l|l|l|l|}
\hline \multicolumn{1}{|c|}{ Construct } & $\mathbf{N}$ & $\begin{array}{c}\text { Cronbach's } \\
\text { alpha }\end{array}$ & \multicolumn{1}{|c|}{ KMO } & $\begin{array}{c}\text { \% of } \\
\text { Variance }\end{array}$ & \multicolumn{1}{|c|}{ AVE } & \multicolumn{1}{c|}{ CR } & $\begin{array}{c}\text { SMC } \\
\text { Min }\end{array}$ & $\begin{array}{c}\text { SMC } \\
\text { Max }\end{array}$ \\
\hline Pathos & 5 & 0.734 & 0.708 & 49.409 & 0.494 & 0.828 & .220 & .375 \\
\hline Logos & 5 & 0.796 & 0.729 & 56.450 & 0.564 & 0.866 & .382 & .523 \\
\hline OGP & 5 & 0.803 & 0.761 & 58.036 & 0.580 & 0.872 & .280 & .581 \\
\hline
\end{tabular}

Source: SPSS 23.0 output 


\section{Confirmatory Factor Analysis (CFA)}

The confirmatory factor analysis was conducted to reconfirm the results obtained from exploratory factor analysis. The confirmatory factor analysis was done to finalize the construct for further analysis of the measurement model and the structural model. All the required model fit indices (GFI, AGFI, TLI, CFI, NFI, and RMSEA) were used for good model fit. The minimum CMIN/DF was achieved for each construct under the measurement model and the structural model.

\section{CFA for Pathos}

Figure 1 depicts the construct Pathos $(\mathrm{P})$ having five items. The rectangular shape represents the observed variables. The oval shape represents the latent variable.

The model fit indices show that the CFA model for pathos is a good fit model.

Figure 1.CFA for pathos (Source: AMOS 23.0 output)

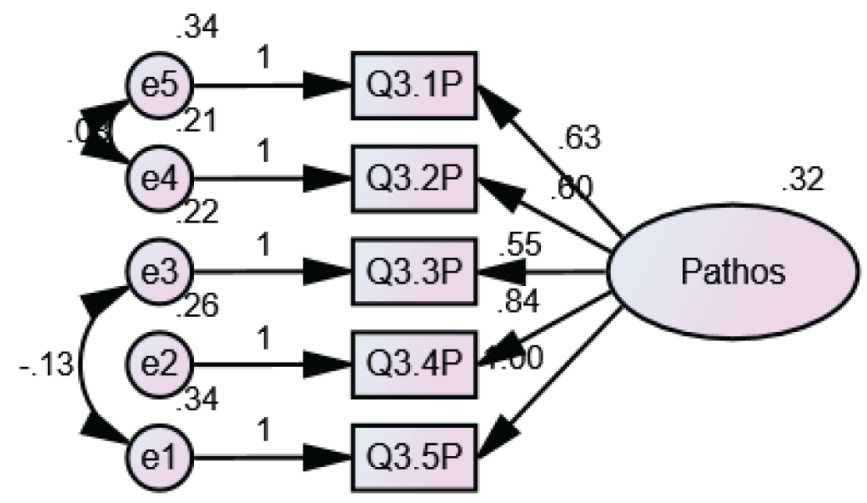

\section{CFA for Logos}

Figure 2 depicts the construct Logos (L) having five items. The rectangular shape represents the observed variables. The oval shape represents the latent variable.

The model fit indices show that the CFA model for logos is a good fit model.

\section{CFA for Online Goods Purchasing (OGP)}

Figure 3 depicts that the construct Online Goods Purchasing (OGP) having five items. The rectangular shape represents the observed variables. The oval shape represents the latent variable.

The model fit indices show that the CFA model for online goods purchasing is a good fit model.

Table 3. Model fit indices for pathos

\begin{tabular}{|c|c|c|c|c|c|}
\hline \multicolumn{2}{|c|}{ CMIN } & DF & \multicolumn{2}{c|}{ P } & CMIN/DF \\
\hline \multicolumn{2}{|c|}{7.175} & 3 & \multicolumn{2}{c|}{.067} & 2.392 \\
\hline GFI & A GFI & TLI & CFI & NFI & RMSEA \\
\hline .993 & .963 & .967 & .990 & .983 & .061 \\
\hline
\end{tabular}


Figure 2. CFA for logos (Source: AMOS 23.0 output)

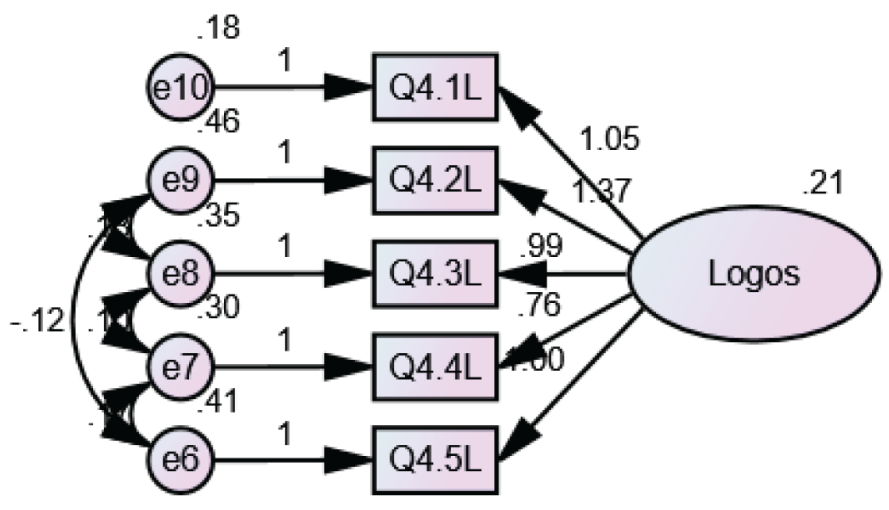

Table 4. Model fit indices for logos

\begin{tabular}{|c|c|c|c|c|c|}
\hline \multicolumn{2}{|c|}{ CMIN } & DF & \multicolumn{2}{c|}{ P } & CMIN/DF \\
\hline \multicolumn{2}{|c|}{1.495} & 1 & \multicolumn{2}{c|}{.222} & 1.495 \\
\hline GFI & A GFI & TLI & CFI & NFI & RMSEA \\
\hline 998 & .976 & .993 & .999 & .998 & .036 \\
\hline
\end{tabular}

Source: AMOS 23.0 output

Figure 3. CFA for online goods purchasing (OGP) (Source: AMOS 23.0 output)

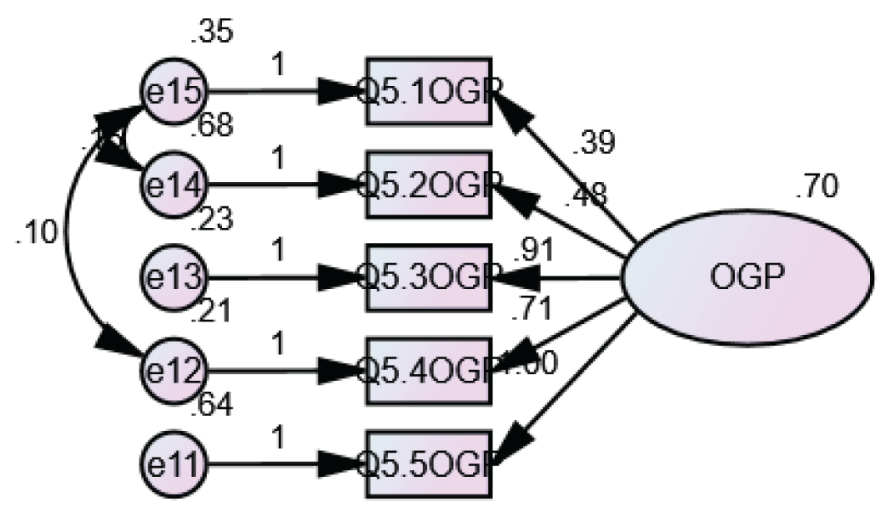

Table 5. Model fit indices for online goods purchasing

\begin{tabular}{|r|r|r|r|r|r|}
\hline \multicolumn{2}{|c|}{ CMIN } & \multicolumn{1}{c|}{ DF } & \multicolumn{2}{c|}{ P } & CMIN/DF \\
\hline \multicolumn{2}{|c|}{14.493} & 3 & \multicolumn{2}{r|}{.002} & 4.831 \\
\hline GFI & AGFI & TLI & CFI & NFI & RMSEA \\
\hline .985 & .926 & .945 & .984 & .980 & .101 \\
\hline
\end{tabular}




\section{Demographic Variables}

Age, gender, and education profile are analyzed for the classification of respondents in a different group. The age is studied in four categories as 20 to 30 years, 31 to 40 years, 41 to 50 years, 51 to 60 years, the gender is analyzed in two groups as male and female, and educational qualifications of respondents are analyzed in four categories as up to $10^{\text {th }}$ standard, up to $12^{\text {th }}$ standard, up to graduate and up to postgraduate level. The following information is given in tabular format for clear understanding. This information is also explained through the table and pie chart (See Table 6 and Figure 4).

Figure 4 depicts that $142(37.37 \%)$ were males and $238(62.63 \%)$ females respondents in the study of online goods purchasing. $66.32 \%$ of respondents were educated up to graduate level and, $50.53 \%$ belong to the age group of $20-30$ years.

In this study, gender is used as a moderating variable. $37.37 \%$ of respondents were males and $62.63 \%$ were females. $66.3 \%$ of respondents were educated up to graduate level and $50.5 \%$ belonged to the age group of 20-30 years as they are comfortable with the new-age mobile technology in comparison to the older ones. Moreover, the money for the shopping is also being paid by their parents through the payment mode of COD (Cash on Delivery), Debit card, Credit Card, or Net Banking.

Table 6. Demographic variables

\begin{tabular}{|c|c|c|c|c|}
\hline SN & Grouping Variable & Categories & Frequency & Percentage \\
\hline 1 & Age & 20 to 30 years & 192 & 50.5 \\
\hline & & 31 to 40 years & 123 & 32.4 \\
\hline & & 41 to 50 years & 41 & 10.8 \\
\hline 2 & Gender & 51 to 60 years & 24 & 6.3 \\
\hline & & Male & 238 & 37.4 \\
\hline 3 & Education & Female & 142 & 3.2 \\
\hline & & Up to $10^{\text {th }}$ & 12 & 7.4 \\
\hline & & Up to $12^{\text {th }}$ & 28 & 66.3 \\
\hline
\end{tabular}

Source: SPSS 23.0 output

\section{RESULTS}

The results of this study comprised under measurement model, correlation matrix, and structural model.

\section{Measurement Model}

Figure 5 depicts the measurement model having three constructs named Pathos (P), Logos (L), and Online Goods Purchase (OGP). Each constructs having five items. The rectangular shape represents the observed variables. The oval shape represents the latent variable.

All factor loadings (regression weights) are greater than 0.300 for five items of each construct under Pathos, Logos, and Online Goods Purchase; hence the factor loadings of each item under construct are acceptable in the study. 
Figure 4. Demographic profile of the respondents (Source: SPSS 23.0 output)
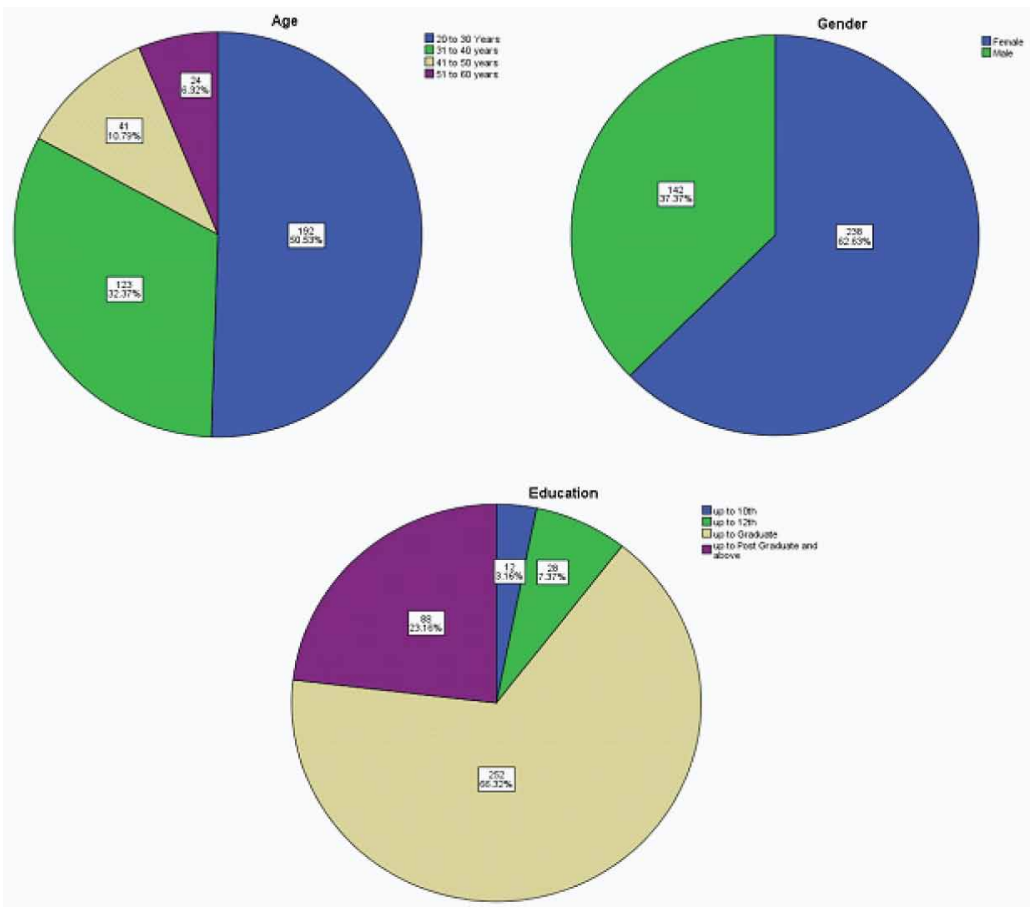

Figure 5. Measurement model (Source: AMOS 23.0 output)

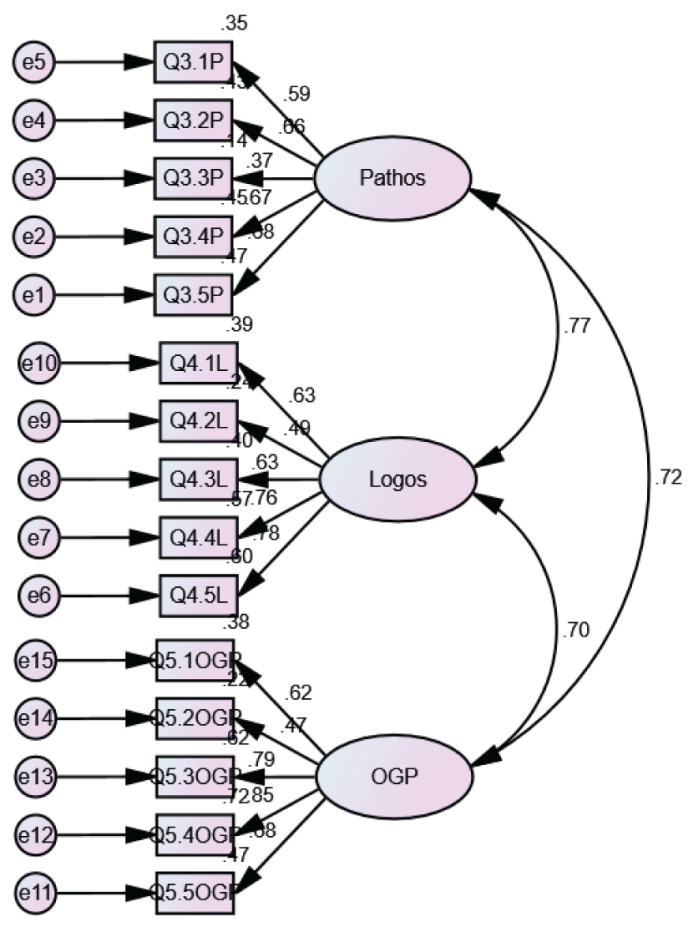


Table 7. Standardized regression weights: items

\begin{tabular}{|c|c|c|c|}
\hline & & & Estimate \\
\hline Q3.5P & $<--$ & Pathos & .685 \\
\hline Q3.4P & $<--$ & Pathos & .373 \\
\hline Q3.3P & $<--$ & Pathos & .659 \\
\hline Q3.2P & $<---$ & Pathos & .589 \\
\hline Q3.1P & $<---$ & Pathos & .777 \\
\hline Q4.5L & $<--$ & Logos & .634 \\
\hline Q4.4L & $<---$ & Logos & .495 \\
\hline Q4.3L & $<---$ & Logos & .628 \\
\hline Q4.2L & $<--$ & Logos & .684 \\
\hline Q4.1L & $<--$ & Logos & .851 \\
\hline Q5.5OGP & $<--$ & OGP & .790 \\
\hline Q5.4OGP & $<--$ & OGP & OGP \\
\hline Q5.3OGP & $<--$ & & \\
\hline
\end{tabular}

Source: AMOS 23.0 output

\section{Correlation Matrix}

There is a high positive correlation $(0.715,0.703$, and 0.771$)$ among pathos, logos, and online good, purchasing (OGP) constructs, therefore this shows that all the constructs are having a relationship among them. This relationship can be further checked through the path analysis under the structural equation modeling.

\section{Structural Model}

Figure 6 depicts the unstandardized estimate of the structural model having three constructs as Pathos, Logos, and Online Goods Purchasing (OGP). The unstandardized coefficients are model parameter estimates based on the analysis of raw data. It represents the amount by which the dependent variable changes if we change the independent variable by one unit keeping other independent variables constant.

Figure 7 depicts the Standardized estimate of the structural model having three constructs as Pathos, Logos, and Online Goods Purchasing (OGP). The standardized coefficients are model parameter estimates based on the analysis of standardized data in the sense that all variables are supposed to have unit variance. The standardized coefficient is measured in the unit of standard

Table 8. Correlation matrix

\begin{tabular}{|l|l|l|c|c|}
\hline & & & Estimate & P \\
\hline Pathos & $<->$ & OGP & $.715^{*}$ & .000 \\
\hline Logos & $<->$ & OGP & $.703^{*}$ & .000 \\
\hline Pathos & $<->$ & Logos & $.771^{*}$ & .000 \\
\hline
\end{tabular}

${ }^{*}$ Correlation is significant at the 0.01 level (two-tailed)

Source: AMOS 23.0 output 
Figure 6. Structural model (unstandardized estimate) (Source: AMOS 23.0 output)

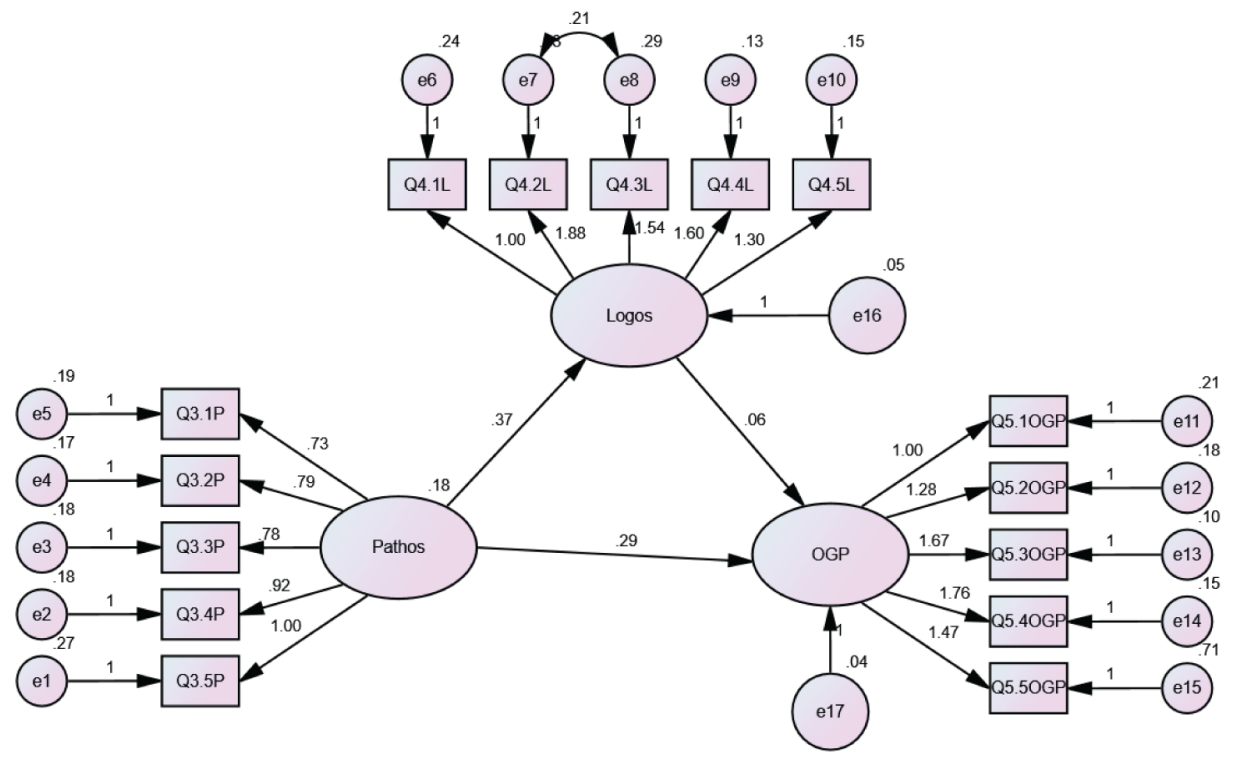

Figure 7. Structural model (standardized estimate) (Source: AMOS 23.0 output)

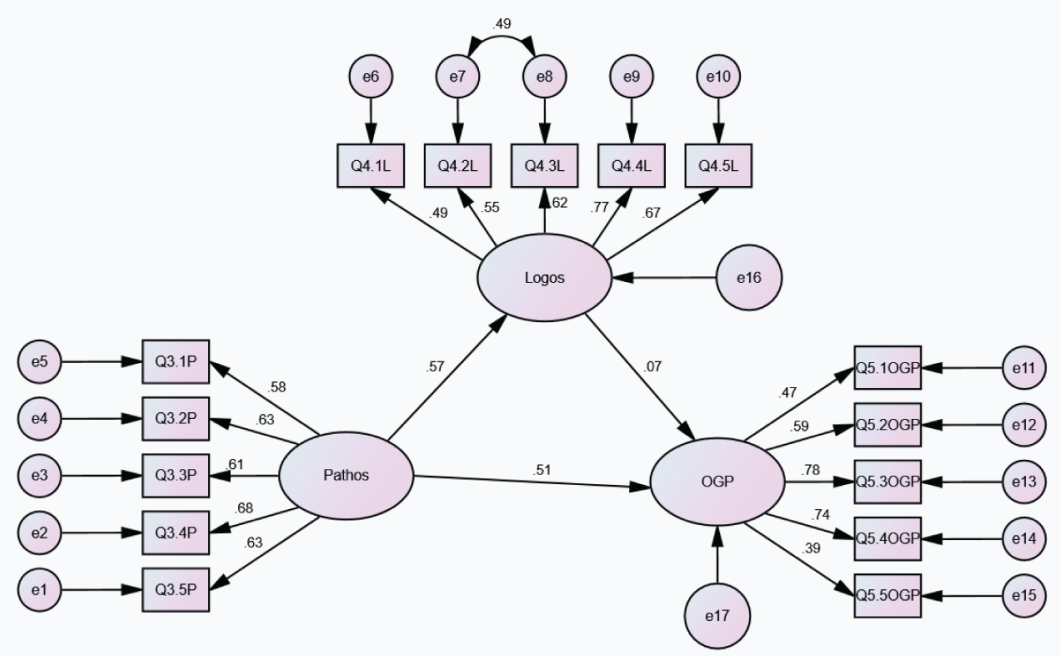


Table 9. Standardized regression weights: constructs

\begin{tabular}{|l|l|l|l|l|l|l|l|}
\hline & & & \multicolumn{1}{|c|}{ Estimate } & \multicolumn{1}{c|}{ S.E. } & \multicolumn{1}{c|}{ C.R. } & \multicolumn{1}{c|}{ p value } & \multicolumn{1}{c|}{ Results } \\
\hline Logos & $<---$ & Pathos & .572 & .077 & 4.856 & .000 & Significant \\
\hline OGP & $<---$ & Pathos & .513 & .076 & 3.892 & .000 & Significant \\
\hline OGP & $<---$ & Logos & .067 & .090 & .647 & .518 & Insignificant \\
\hline
\end{tabular}

Source: AMOS 23.0 output

deviation. The standardized coefficient is found by multiplying the unstandardized coefficient by the ratio of the standard deviations of the independent variable and dependent variable.

It is clear that the sig value ( $p$-value is .000 ) is less than 0.05 , for the path pathos with logos and OGP, hence it can be concluded that there is an effect of pathos on logos and OGP. That simply means that emotional behavior affects logical behavior as well as online goods purchasing behavior. The sig value (p-value is .518) is more than 0.05 for the path logos and OGP, therefore it can be concluded that there is no effect of logical behavior on the purchase of the online goods as for the whole respondents without differentiating male and female respondents. The standardized regression weight is 0.572 for the path between Pathos and Logos, hence, if there is one standard deviation increase in pathos then there is a 0.572 standard deviation increase in logos. Since the standard error (S.E.) is low (0.077), hence the sample size is sufficiently large, and it truly belongs to the selected population. Since the critical ratio (C.R. $=4.856)$ is $>1.96$ for a regression weight of 0.572 , hence the path between pathos and logos is significant at the $5 \%$ significance level. The standardized regression weight is 0.513 for the path between Pathos and OGP; hence, if there is one standard deviation increase in pathos then there is a 0.513 standard deviation increase in OGP. Since the standard error (S.E.) is low (0.076), hence the sample size is sufficiently large, and it truly belongs to the selected population. Since the critical ratio $($ C.R. $=3.892)$ is $>1.96$ for a regression weight of 0.513 , hence the path between pathos and OGP is significant at the 5\% significance level. The standardized regression weight is 0.067 for the path between Logos and OGP; hence, if there is one standard deviation increase in logos then there is a 0.067 standard deviation increase in OGP. Since the standard error (S.E.) is low (0.090), hence the sample size is sufficiently large, and it truly belongs to the selected population. Since the critical ratio (C.R. $=0.647$ ) is $<1.645$ for a regression weight of 0.067 , hence the path between logos and OGP is insignificant at the 10\% significance level. (Z Score 1.645, 1.96, 2.76 represents 90\%, 95\%, 99\% confidence Interval respectively)]. The next level analysis (known as moderating or group analysis) is to know the effect of these constructs by differentiating male and female respondents (see Table 9).

\section{MULTIPLE GROUP ANALYSIS AND MODERATING HYPOTHESES TESTING}

For moderating hypothesis testing, three approaches were used as Chi-square Difference Test, Pairwise Parameter Comparisons (Constrained Model), and Nested Model Comparisons. Gender was used as a moderator in this study. The results of the three approaches are as follows.

\section{Approach 1: Chi-Square Difference Test}

The path diagram of the baseline model (unconstrained model) for male respondents ( 142 respondents) with unstandardized estimates is presented in figure 8 and the baseline model (unconstrained model) for female respondents ( 238 respondents) with unstandardized estimates is presented in figure 9.

The unconstrained model or baseline model is defined as when there is no assumption.

The unconstrained model or baseline model is defined as when there is no assumption.

By using multiple-group analysis, the constrained model presents the parameter estimates in measurement and structural weights that were constrained to be equal in both groups. The constrained 
Figure 8. The baseline model (unconstrained model) for male (Source: AMOS 23.0 output)

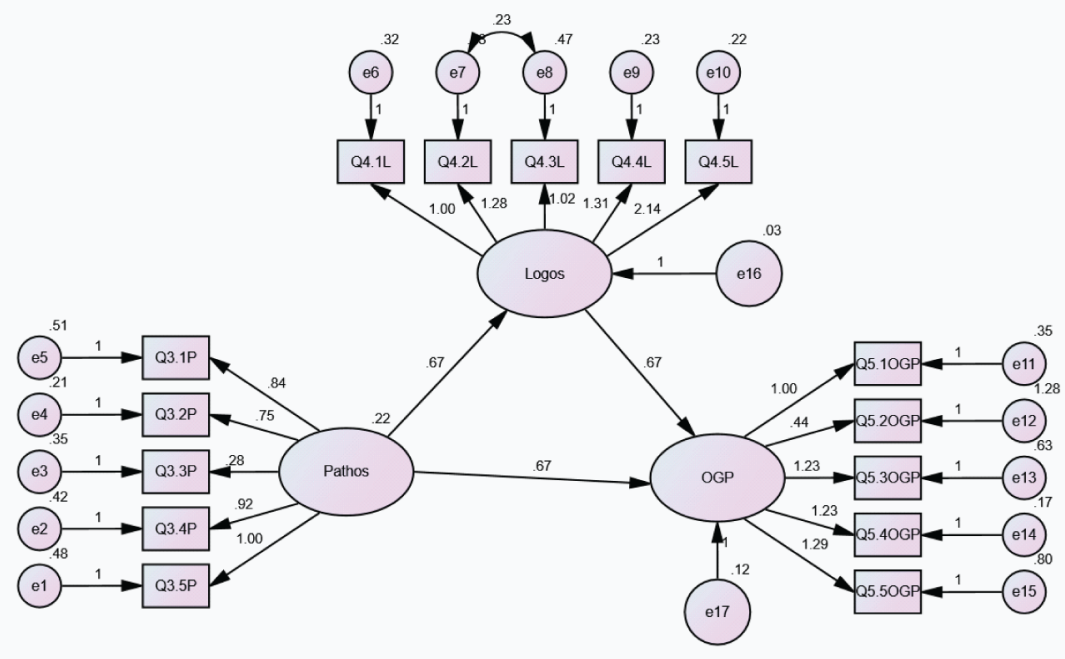

Figure 9. The baseline model (unconstrained model) for female (Source: AMOS 23.0 output)

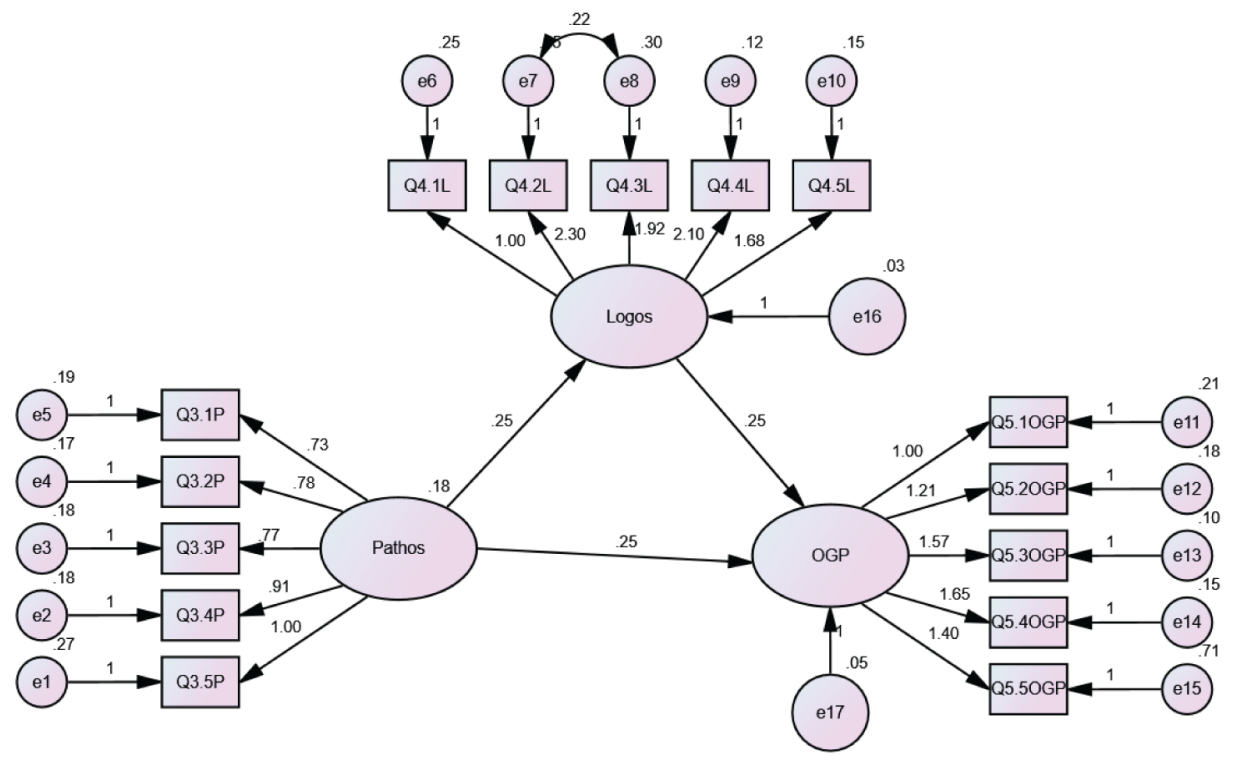


models (structural weights models) for males and females are presented in figure 9 and figure 10 . The constrained model is defined as an assumption that $\mathrm{F}=\mathrm{M}$ : Female and male group estimates of pathos, logos on online purchasing behavior are the same.

The result shows that the degree of freedom (DF) increases $=1(177-176), \mathrm{CMIN}$ increases $=$ 29.018 (970.457-941.439), $\mathrm{p}=0.000$. The null hypothesis H0a is rejected, the direct paths from pathos and logos towards online goods purchase differ for males and females because there is a difference across groups, (See figures 8 and 9).

Since P-value is less than 0.05 for Pathos $>$ Logos, Logos $>$ OGP, hence the two direct paths Pathos $>$ Logos, Logos $>$ OGP are statistically significant whereas the p-value is greater than .05 for Pathos $>$ OGP, hence one direct path Pathos $>$ OGP are statistically insignificant for Male that also confirms that males were not governed by the emotions.

Since the p-value is less than 0.05 for Pathos $>$ Logos, Pathos $>$ OGP, hence the two direct paths Pathos $>$ Logos, Pathos $>$ OGP are statistically significant whereas P-value is greater than 0.05 for Logos $>$ PGP, hence one direct path Logos $>$ PGP are statistically insignificant for Female that also confirm that females were not governed by Logic. In summary, the moderating hypothesis or alternative hypothesis $\mathrm{H} 1 \mathrm{a}$ is accepted, which suggests that the influence of pathos and logos on OGP is moderated by gender.

\section{Approach 2: Pairwise Parameter Comparisons (Constrained Model)}

Since the critical ratio for the difference between parameters (Baseline Model / Unconstrained Model) - 4.572 is beyond the range, therefore it was safe to reject the null hypothesis $\mathrm{H}_{\mathrm{b}}$ and concluded that there is a significant difference between female and male group estimates of pathos, logos on online purchasing behavior. [(If the critical ratio for the difference is between - 1.96 to +1.96 (for $95 \%$ confidence interval, the $\mathrm{z}$ is 1.96), then accept the null hypothesis, else reject the null hypothesis. $(\mathrm{M}=$ Male, $\mathrm{F}=$ Female $)$ ] [The $\mathrm{z}$ value is used for standard normal curve under area properties. The $\mathrm{z}=(\mathrm{x}-$ mean $) /$ standard deviation] [For standard normal curve the mean is zero and the standard deviation is unity].

\section{Approach 3: Nested Model Comparisons}

The constrained model is defined as an assumption that $\mathrm{F}=\mathrm{M}$ : Female and male group estimates of pathos, logos on online purchasing behavior are the same. The unconstrained model or baseline model is defined as when there is no assumption.

Since $\mathrm{P}$ value $0.000<0.05$, hence it is safe to reject null hypothesis $\mathrm{H}_{\mathrm{c}}$, therefore it can be concluded that both the Constrained model and Baseline Model (Unconstrained Model) are not the same, therefore both the constrained and unconstrained model are different. Finally, the researcher can conclude that the influence of pathos (emotional behavior) and logos (logical behavior) on online goods purchasing was moderated by gender.

\section{DISCUSSION AND CONCLUSION}

Human behavior in itself is complex, irrational, non-linear, non-parametric, and time-variant. On top of that, gender-specific behavior also plays a role as both genders have different physical, biological, and mental stature. In a country like India, both genders are raised differently. The expectations of society are also different from both. With changing times, society is also changing but in current times, our study shows that females are more emotionally vulnerable for marketers when compared to males. Females are more susceptible to sales, discounts, offers, and other advertisements. In major households, the purchase decision is taken by the lady of the house. With the advent of online shopping, males are also participating in day-to-day household shopping. But until there comes a significant social change, females of any age will continue to drive the consumer goods buying process. This stands true for both low involvements as well as high involvement products. 
Figure 10. The constrained model for male (Source: AMOS 23.0 output)

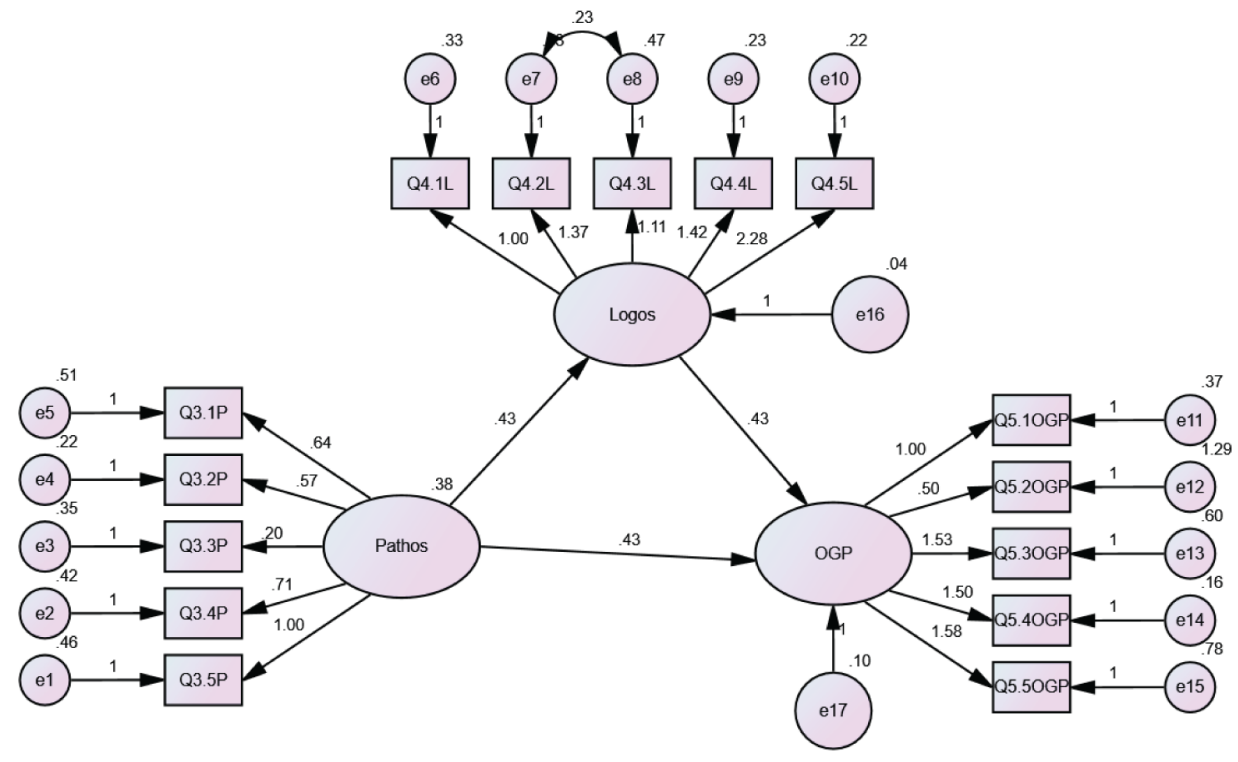

Figure 11. The constrained model for female (Source: AMOS 23.0 output)

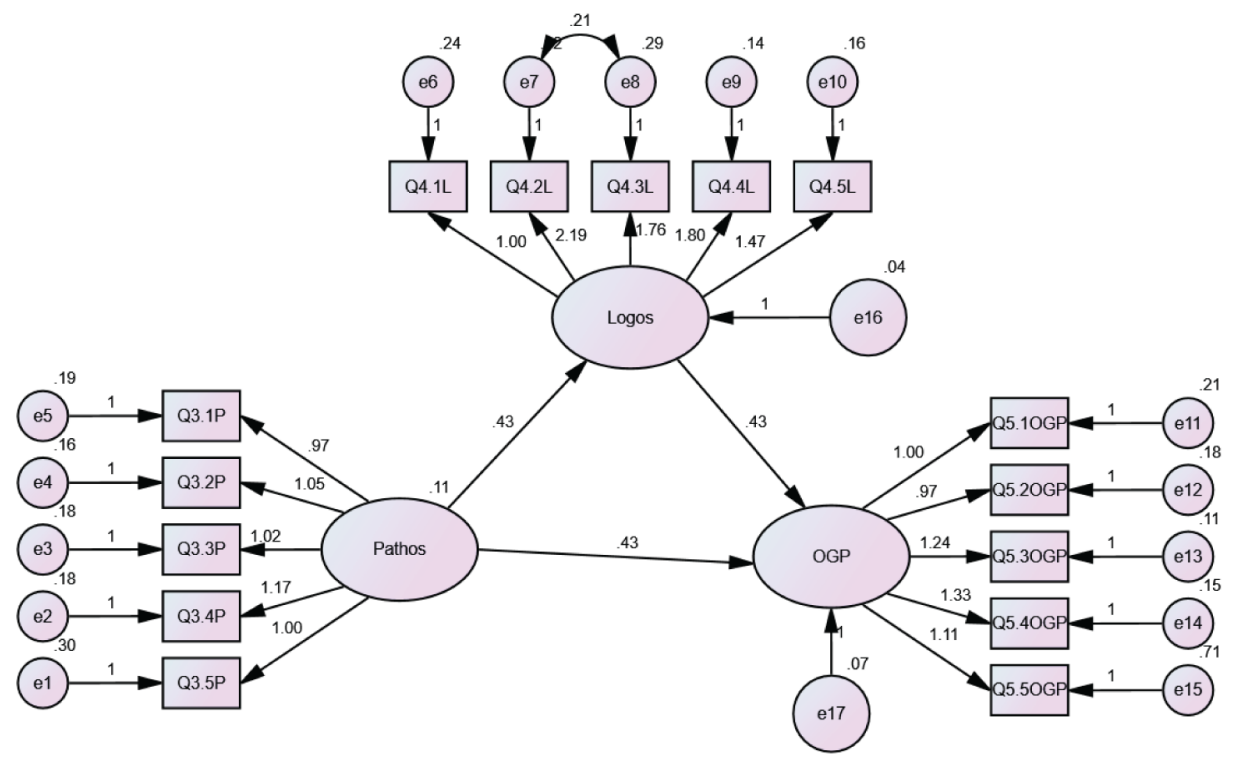


Table 10. The chi-square difference test

\begin{tabular}{|l|l|l|l|l|}
\hline \multicolumn{1}{|c|}{ Model } & \multicolumn{1}{|c|}{ Chi-square } & \multicolumn{1}{c|}{ Df } & p value & Reject/Accept Ho \\
\hline $\begin{array}{l}\text { Baseline } \\
\text { (Unconstrained) } \\
\text { Model }\end{array}$ & 941.439 & 176 & & \\
\hline $\begin{array}{l}\text { Constrained } \\
\text { Structural Weights) } \\
\text { Model }\end{array}$ & 970.457 & 177 & & \\
\hline $\begin{array}{l}\text { The chi-square } \\
\text { Difference Test }\end{array}$ & 29.018 & 1 & 0.000 & Reject Null \\
\hline
\end{tabular}

Source: Author's Calculation

Table 11. Standardized regression weights: (male - default model)

\begin{tabular}{|l|l|l|l|l|l|}
\hline & & & \multicolumn{1}{|c|}{ Estimate } & \multicolumn{1}{c|}{ p value } & \multicolumn{1}{c|}{ Results } \\
\hline Logos & $<--$ & Pathos & .878 & .000 & Significant \\
\hline OGP & $<---$ & Pathos & -.266 & .437 & Insignificant \\
\hline OGP & $<--$ & Logos & 1.051 & .003 & Significant \\
\hline
\end{tabular}

Source: AMOS 23.0 output

Table 12. Standardized regression weights: (female - default model)

\begin{tabular}{|l|l|l|l|l|l|}
\hline & & & \multicolumn{1}{|c|}{ Estimate } & \multicolumn{1}{|c|}{ p value } & \multicolumn{1}{|c|}{ Results } \\
\hline Logos & $<--$ & Pathos & .572 & .000 & Significant \\
\hline OGP & $<---$ & Pathos & .513 & .000 & Significant \\
\hline OGP & $<---$ & Logos & .067 & .518 & Insignificant \\
\hline
\end{tabular}

Source: AMOS 23.0 output

Based on the data analysis and interpretation, it is finally concluded that the two direct paths Pathos $>$ Logos, Logos $>$ OGP are statistically significant whereas one direct path Pathos $>$ OGP is statistically insignificant for males that confirm that males are more governed by logic. The two direct paths Pathos $>$ Logos, Pathos $>$ OGP are statistically significant whereas one direct path Logos $>$ PGP is statistically insignificant for females that also confirm that females were driven by emotions. By and large, this behavior is studied but there can be exceptions to this (See Table 11, 12).

Since the critical ratio for the difference between parameters (Baseline Model / Unconstrained Model) - 4.572 is beyond the range, therefore it was safe to reject the null hypothesis $\mathrm{H}_{\mathrm{b}}$ and concluded that there is a significant difference between female and male group estimates of pathos, logos on online purchasing behavior (see Table 14).

It is also confirmed that there is a significant difference between female and male group estimates of pathos, logos on online purchasing behavior. Both the Constrained model and Baseline Model (Unconstrained Model) are different. Finally, the researcher can conclude that the influence of pathos (emotional behavior) and logos (logical behavior) on online goods purchasing is moderated by gender (see Table 15).

The practical and social implications of this study will help to know the exact status quo of the pathos, and logos on online goods purchasing. This research will be beneficial not only for the online customers but also for the e-commerce companies who are in the online trading of goods and services. 
Table 13. Critical ratios for differences between parameters (constrained model)

\begin{tabular}{|c|c|}
\hline & $\mathrm{M}$ \\
\hline $\mathrm{M}$ & 0.000 \\
\hline
\end{tabular}

Source: AMOS 23.0 output

Table 14. Critical ratios for differences between parameters (baseline model (unconstrained model))

\begin{tabular}{|c|c|c|}
\hline & $\mathrm{M}$ & $\mathrm{F}$ \\
\hline $\mathrm{M}$ & 0.000 & \\
\hline $\mathrm{F}$ & -4.572 & 0.000 \\
\hline
\end{tabular}

Source: AMOS 23.0 output

Table 15. Nested model comparisons: assuming model baseline model (unconstrained model) to be correct

\begin{tabular}{|l|l|l|l|}
\hline \multicolumn{1}{|c|}{ Model } & \multicolumn{1}{c|}{ DF } & \multicolumn{1}{c|}{ CMIN } & p-value \\
\hline Constrained Model & 1 & 29.017 & .000 \\
\hline
\end{tabular}

Source: AMOS 23.0 output

The social implication of this study will help in knowing the emotional and logical behavior of the customer while purchasing goods online through various e-commerce platforms. In this study, only gender is used as a moderator but it is suggested that future researchers can use other moderators like age, educational qualification, occupation, and monthly income, etc. for more in-depth study.

\section{Funding}

Nil

\section{Availability of Data and Materials}

Primary data was collected using Google Forms. The structured questionnaire was designed on the online Google platform for a fast and easy collection of responses.

\section{Ethical Consent}

The ethical consent was taken by each respondent by making them tick on the mandatory checklist of the disclaimer at the beginning of the questionnaire to proceed with filling up the questionnaire. The disclaimer was stated as "Any information filled in the questionnaire will be anonymous and shall not be used for any commercial purpose both during the research and after its publication". All the respondents have given their due consent for this study.

\section{Authors' Contributions}

All authors read and approved the final manuscript.

\section{Competing Interests}

The authors declare that they have no competing interests. 


\section{REFERENCES}

Bolatito, O. (2012). New Media and Mass Communication Linkage between Persuasion principles and Advertising. www.iiste.org

Chu, H.-L., Deng, Y.-S., \& Chuang, M.-C. (2014). Investigating the Persuasiveness of E-Commerce Product Pages within a Rhetorical Perspective. International Journal of Business and Management, 9(4), 31-43. doi:10.5539/ijbm.v9n4p31

Das, A., Gollapudi, S., \& Kiciman, E. (2014). Effect of Persuasion on Information Diffusion in Social Networks. http://research.microsoft.com/pubs/217325/persuasion_2014-05-19.pdf

Gabriel, R., Thesis, T., Karreman, J., \& Fenko, A. (2016). The consumer-to-consumer persuasion: Application of rhetoric appeals in consumer's reviews Faculty of Behavioural, Management and Social Sciences. BMS.

Garbarino, E., \& Strahilevitz, M. (2004). Gender differences in the perceived risk of buying online and the effects of receiving a site recommendation. Journal of Business Research, 57(7), 768-775. doi:10.1016/S01482963(02)00363-6

Higgins, C., \& Walker, R. (2012). Ethos, logos, pathos: Strategies of persuasion in social/environmental reports. Accounting Forum, 36(3), 194-208. doi:10.1016/j.accfor.2012.02.003

Isai, K. I. A., Lin, T. M., Ching, H. S., Selvajothi, R., \& Maruthai, E. (2020). Using Rhetorical Approach of Ethos, Pathos, and Logos by Malaysian Engineering Students in Persuasive Email Writings. Malaysian Journal of Social Sciences and Humanities, 5(4), 19-33. doi:10.47405/mjssh.v5i4.386

Jiradilok, T., Malisuwan, S., Madan, N., \& Sivaraks, J. (2014). The Impact of Customer Satisfaction on Online Purchasing: A Case Study Analysis in Thailand. Journal of Economics, Business, and Management, 2(1), 5-11. doi:10.7763/JOEBM.2014.V2.89

Kantharaju, R. B., Pease, A., De Franco, D., \& Pelachaud, C. (2018). Is two better than one? Effects of multiple agents on user persuasion. Proceedings of the 18th International Conference on Intelligent Virtual Agents, IVA 2018, 255-262. doi:10.1145/3267851.3267890

Kiholm, M., \& Gårdemyr, A. (2017). The strategic use of rhetorical proofs in transformational advertising A case study about SAS. Academic Press.

Lee, D., Hosanagar, K., \& Nair, H. S. (2018). Advertising content and consumer engagement on social media: Evidence from Facebook. Management Science, 64(11), 5105-5131. doi:10.1287/mnsc.2017.2902

Lim, P. L., \& Rashad, Y. (2014). Does Gender Play a Role in Online Consumer Behavior? Does Gender Play a Role in Online Consumer Behavior? 14(7). https://www.researchgate.net/publication/268221331_Does_Gender_ Play_A_Role_In_Online_Consumer_Behavior

McCormack, K. C. (2014). Ethos, Pathos, and Logos: The Benefits of Aristotelian Rhetoric in the Courtroom. Washington University Jurisprudence Review, 131(1), 131-155. https://openscholarship.wustl.edu/law_ jurisprudence/vol7/iss $1 / 9$

Peleckis, K., \& Peleckiene, V. (2015). Persuasion in Business Negotiations: Strategic Orientations and Rhetorical Argumentation. Universal Journal of Management, 3(10), 413-422. doi:10.13189/ujm.2015.031006

Sarkar, R. (2015). The Role of Gender in Online Shopping-a Literature Review. www.gjesss.co.in

Scaraboto, D., \& Pereira, S. J. N. (2013). Rhetorical strategies of consumer activists: Reframing market offers to promote change. BAR - Brazilian Administration Review, 10(4), 389-414. doi:10.1590/S180776922013000400003

Ting, S. H. (2018). Ethos, logos, and pathos in university students' informal requests. GEMA Online Journal of Language Studies, 18(1), 234-251. doi:10.17576/gema-2018-1801-14

Verma, V., Anand, S., \& Mishra, K. (2020). The Pathos and Logos Affecting Online Purchasing Behavior. International Journal of Online Marketing, 10(4), 41-56. doi:10.4018/IJOM.2020100103

Wilkowski, C., \& Park, W. (2015). Use of Rhetoric in 1960's Protest Music: A Case Study of Bob Dylan's Music. Rollins College. 
Xiao, L., Guo, F., Yu, F., \& Liu, S. (2019). The effects of online shopping context cues on consumers' purchase intention for cross-border E-Commerce sustainability. Sustainability (Switzerland), 11(10), 1-24. doi:10.3390/ su11102777 